\title{
Demir Bazlı Nano-Sıvının Tek-Faz ve Havuz Kaynama Isı Transferi Şartlarında Ekserji Analizi
}

\author{
Exergy Analysis of Ferrofluid Nanofluid under Single-Phase and Pool Boiling Conditions
}

\author{
Mehmed Rafet ÖZDEMİR ${ }^{\mathbf{1}}$ \\ ${ }^{1}$ Marmara Üniversitesi, Mühendislik Fakültesi, Makine Mühendisliği Bölümü, 34722, İstanbul, Türkiye
}

$\ddot{O} \mathbf{z}$

Son yıllarda termal-sıvı uygulamaları artan 1 sı akısını karşılamak için en sık kullanılan yöntemlerden biri olmaya başlamıştır. $\mathrm{Bu}$ uygulamalardan en popüler olanlarından biri sıvıya nano-parçacık karıştırarak 1sı transfer hızını arttırmaya çalışmaktır. Teoride kabul gören bu yöntem için farklı araştırma gruplarından farklı sonuçlar gelmekle birlikte kesin bir yargıya henüz tam olarak ulaşıldığı söylenemez. Sıvıya nano-parçacık eklemenin en zorlu yanı, birçok çalışmada belirtildiği gibi nanoparçacıkların yüzey üzerinde kümelenmeye ve çökelmeye meyilli olması ve bu durumun olması halinde 1sı transferine negatif etki yapmasıdır. Bu özelliklerinden ötürü nano-parçacıkların sistem üzerinde kararsız davranış oluşturduğu da bazı çalışmalarda rapor edilmiştir. $\mathrm{Bu}$ çalışmada ana sıvı olarak suya $\mathrm{Fe}_{3} \mathrm{O}_{4}$ nano-parçacıkları eklenen sistemin ekserji analizi yapılmıştır. Burada en önemli nokta, sistemin manyetik kuvvete maruz bırakılması olup bu sayede çökelme ve kümelenmeye firsat verilmeyecek olmasıdır. Bu çalışmada literatürden farklı olarak sistemin tek-fazlı akış ve havuz kaynama şartlarındaki verimi ekserjetik verim üzerinden değerlendirilecektir. Sonuçlar saf su, su- $\mathrm{Fe}_{3} \mathrm{O}_{4}$ nano-sıvısı ve manyetik kuvvet altındaki su-Fe $\mathrm{O}_{4}$ nano-sıv1s1 şeklinde sunulup ekserji yıkım oranları karşılaştırılmıştır.

Anahtar kelimeler: nano-sıv1, ekserji analizi, havuz kayanama, tek-fazlı 1sı transferi

\begin{abstract}
In recent years, thermal-liquid applications have become one of the most commonly used methods to meet high heat flux demand. One of the most popular of these applications is to try to enhance the heat transfer rate by mixing nanoparticles into the liquid. Although different results come from different research groups for this method, which is accepted in theory, it cannot be said that a satisfactory conclusion has been reached yet. The most challenging aspect of adding nanoparticles to the liquid is that, as noted in many studies, the nanoparticles tend to cluster and sediment on the surface and, if this happens, have a negative effect on heat transfer. Due to these characteristics, some studies have reported that nanoparticles cause unstable behaviour on the system. In this study, exergy analysis of $\mathrm{Fe}_{3} \mathrm{O}_{4}$-water nanofluid has been performed. The most important point here is that the system is exposed to magnetic force, so that clustering and sedimentation is prevented. In this study, unlike the literature, the efficiency of the system will be evaluated on the basis of exergetic efficiency. The results will be presented for pure water, $\mathrm{Fe}_{3} \mathrm{O}_{4}$-water nanofluid and $\mathrm{Fe}_{3} \mathrm{O}_{4}$-water under magnetic actuation and their exergy destruction rate values will be compared and discussed.
\end{abstract}

Keywords: nanofluids, exergy analysis, pool boiling, single-phase heat transfer

\section{GİRIŞ}

Endüstri 4.0' a geçiş, yüksek enerji ile çalışan akıllı sistemler, yüksek güç tüketen hızlı sunucular ve daha birçok gelişme son ylllarda şahit olduğumuz teknolojik gelişmelerdir. Bu gelişmelerle birlikte başta elektronik cihazlar daha da küçülmüş ve hızlanmış fakat yaydıkları 1sı akısı da çok yüksek seviyelere ulaşmıştır [1-3]. Bu sistemlerin kendi boyutlarındaki mikro ısı değiştiriciler kullanılarak soğutulması da bilim adamları için önemli araştırma konusu olmuştur [4-6]. Bu noktada, son yıllarda sıvı ile soğutma popüler olmakla beraber daha yakın zamanda ana sıvıya nano-parçacık karıştırarak 1sı transferini daha fazla arttırmaya çalışmak birçok çalışmanın konusu olmuştur [7-11]. Bunun en önemli sebebi nano-sıvıların ana sıvılarına göre daha yüksek 1sı iletkenliklerinin olmasıdır [12, 13]. Öte yandan birçok çalışmada gösterildiği üzere yüzey yapısı tek-fazlı ve kaynama isı transferine önemli ölçüde pozitif olarak etki etmektedir [14-17]. Bu noktadan yola çıkarak, baz sıvıya katılan nano-parçacıkların tek-fazlı 1sı transferinde yüzey alanını arttırarak kaynama isı transferinde ise ekstra aktif çekirdeklenme konumları oluşturarak 1S1 transferine katkı verdikleri söylenebilir. Bu bilgilere ek olarak, birkaç çalışmada nano-parçacıkların rastgele 
hareketlerinin ve termoforez etkisinin sistemin genel enerji taşınımını arttırdığı belirtilmiştir $[11,18]$. Nanosıvıların 1sı transferi performansını etkileyen ve en çok karşılaşılan en önemli parametreler kümelenme ve çökelmedir. Bu durumlar oluştuğunda sistemin genel stabilitesini de etkileyerek 1s1 transferine negatif etki yapmaktadir $[19,20]$.

Literatürde kümelenme ve çökelme sorunlarını aşmak için manyetik kuvvetle hareketlendirilen nano-sıvilar kullanılmıştır [20-24]. Şeşen vd. [20] manyetik olarak hareketlendirilen $\mathrm{su}-\mathrm{Fe}_{3} \mathrm{O}_{4}$ nano-sıvisının tek-faz ve havuz kaynama şartları altında 1 sı transferi özelliklerini inceledi. Araştırmacılar, manyetik olarak hareketlendirilen nano-sıvının tek-fazlı durumda \% 29, havuz kaynama şartları altında \% 17 daha yüksek 1s1 transferi katsayısına sahip olduğunu bildirdi. Kurtoğlu vd. [21] manyetik olarak hareketlendirilen nanoparçacıkların mikro pompa üzerinde sıvı kontamine oluşturmadığını gösterdi. Başka bir çalışmada ise, Özdemir vd. [23] çift katmanlı yağ asidi kaplanmış manyetik olarak hareketlendirilen demir bazlı nanosiviların havuz kaynama 1sı transferini inceledi. Sonuçlara göre manyetik kuvvet ile hareketlendirilen nano-sıviların 1S1 transferi performansı manyetik kuvvet olmayan duruma göre \% 42 daha yüksek bulundu. Ayrıca, aynı demir kütlesinde manyetik kuvvetin olduğu durumda çökelme ve kümelenme olayları manyetik kuvvetin olmadığı duruma göre çok daha geç oluştuğu bildirilmiştir. Başka bir çalışmada ise Şeşen vd. [24] ferro-manyetik nano-parçacıkların deneysel olarak tek-fazlı 1Sı transferini özelliklerini inceledi. Çalışmanın sonunda ortalama 1sı transferi katsayısının manyetik kuvvet altında \% 37.5 iyileşme gösterdiği ve sadece ekstradan $5 \mathrm{~W}$ pompa gücü ile bunun sağlandığını bildirdiler.

Yukarıdaki çalışmalarda bahsedilen verim terimi isı transferi hesapları ile sınırlandırılmış olup ekserji analizi göz önünde bulundurulmamıştır. Öte yandan, termodinamik bir yaklaşım araştırması devam etmekte olan manyetik olarak hareket ettirilen demir bazlı nano-sıvıların performanslarını değerlendirmek için önemli bir faktör olabilir. Birçok çalışmada bildirildiği gibi, ekserji, sistemin faydalı enerji miktarı olan iş potansiyelidir. $\mathrm{Bu}$ nedenle, ekserji, sistemlerin performansını değerlendirmek için klasik enerji parametrelerinden daha güçlü bir araç olarak düşünülebilir [25, 26]. Dahası, ekserji analizi bir sürecin sürdürülebilirliği için gerekli olan etkili bir işlem veya kurulumun nasıl seçileceği konusunda güçlü fikirler verebilir [27, 28]. Literatürde nanosıvıların ekserji analizini içeren çalışmalara rastlanmıştır [29-33]. Khaleduzzaman vd. [29] distile su $\quad-\quad \mathrm{Al}_{2} \mathrm{O}_{3}$ nano-sıvisının dikdörtgensel mikrokanallarda ekserji verimini araştırmıştır. Ekserji veriminin nano-parçacık hacimsel oranıla beraber artarken Reynold sayısı ile azaldığını gösterdiler. Başka bir çalışmada ise Esfahani ve Languri [30] sugrafen oksit nano-sıvısı kullanan kabuk-boru tipi 1s1 eşanjörünün ekserji analizini gerçekleşmiştir. Deneyler sırasında baz sıvı olan suyun içerisine grafen oksit miktarı ağırlıkça $\% \quad 0.01 \quad-\quad \% \quad 0.1$ aralığında değiştirilmiştir. Sonuçlar, sıcak sıvı olarak distile sugrafen oksit nano-sıvısının kullanılmasının, hem laminer hem de türbülanslı koşullar altında kabukborulu 1sı eşanjöründe daha az ekserji kaybına yol açtığını göstermiştir. Öte yandan, sıcak sıv1 olarak sadece distile su kullanıldığında laminer şartlarda \% 22 ve türbülanslı şartlarda \% 109 daha yüksek ekserji kaybı yaşandığı gösterilmiştir. Başka bir çalışmada ise Said vd. [31] farklı partikül büyüklüğünde (13 nm ve $20 \mathrm{~nm})$ sabit hacimsel orandaki (\% $\%$.1) Alüminyum nano-parçacıkları içeren $\mathrm{su}-\mathrm{Al}_{2} \mathrm{O}_{3}$ nano sıvısını solar kollektörleri soğutmak için kullanmışlardır. Sistemin genel enerji ve ekserji analizini yapmışlardır. Nanosıvı kararlı duruma geçtikten sonra deneylere başlanmış olup $13 \mathrm{~nm}$ büyüklüğündeki $\mathrm{Al}_{2} \mathrm{O}_{3}$ sıvısının diğer numune kıyasla daha yüksek isı iletkenlik katsayısına sahip olduğunu belirtmişlerdir. Ayrıca deneyler sonucunda $13 \mathrm{~nm}$ büyüklügündeki $\mathrm{Al}_{2} \mathrm{O}_{3}$ - su nano-sıvısının diğer nano-sıvıya göre daha yüksek enerji ve ekserji verimliliğine sahip olduğu gösterilmiştir. Bu bulgulara ek olarak, yazarlar termoekonomik analiz de yapmış olup, nano-sıvılı sistemin geleneksel sistemlere göre daha k1sa geri ödeme süresine sahip olduğunu ve daha az çevresel yan etkilerinin olduğunu belirtmişlerdir. Çok yakın zamandaki bir çalışmada Mukherjee vd. [32] su bazlı $\mathrm{Al}_{2} \mathrm{O}_{3}, \mathrm{TiO}_{2}, \mathrm{CuO}$ ve $\mathrm{SiC}$ nano-sivilarının enerji, ekserji kaybı ve pompa gücü analizlerini dikdörtgensel mikrokanallı 1sı değiştiricilerde sabit 1s1 akısı şartları altında incelediler. Nano-parçacıkların ağırlık yüzdeleri \% 0 - \% 5 aralıklarında değiştirildi. Nanoparçacıkların ağırlık yüzdeleri ana sıvı içerisinde arttıkça oluşan nano-sıvının termal iletkenlik katsayısının da arttı̆̆ nano-parçacık ağırlık yüzdesi artışı sistemin pompa için harcaması gereken güç miktarını ve ekserji kaybını arttırdığı gözlendi. Termal enerji verimliliği $\mathrm{CuO}-$ su nano-sıvısının \%5 ağırlık yüzdesinde maksimum olarak rapor edildi. Sonuç olarak, araştırmacılar $\mathrm{CuO}-$ su nano sivisinı $\mathrm{Al}_{2} \mathrm{O}_{3}$ - su, $\mathrm{TiO}_{2}$ - su ve $\mathrm{SiC}$ - su nanosıvılarına göre daha önerilebilir olduğu kanısına vardı.

Yukarıdaki literatür taramasından görüldüğü üzere bazı çalışmalarda nano-sıvıların soğutma sistemlerinde kullanımı 1sı transferi performansını ve termal enerji verimliliğini arttırmıştır. Diğer taraftan, bazı çalışmalarda ise nano-sıvıların çökelme, kümelenme ve kararsız davranışlarından dolayı 1sı transferi performansına etki etmediği ya da negatif yönde etki ettiği belirtilmiştir. Bununla birlikte manyetik kuvvete maruz kalan manyetik bazlı nano-sıvılar için yapılan termal-hidrolik performans analizini içeren çalışmalar oldukça nadirdir. Bu çalışmalarda manyetik kuvvetin nano-sıvılarda görülen çökelme, kümelenme ve kararsız davranışlara nano-parçacıkların rastgele hareketlerinin ve termoforez etkisi sayesinde çözüm getirdiği söylenmiştir. Öte yandan bu nadir 
çalışmalarda da verim analizleri birinci yasa üzerinden incelenmiş olup ekserji analizi hesaba katılmamıştır. $\mathrm{Bu}$ çalışmada, manyetik kuvvete maruz bırakılan $\mathrm{Fe}_{3} \mathrm{O}_{4}$ nano-parçacıklarından oluşan $\mathrm{Fe}_{3} \mathrm{O}_{4}$ - su nanosıvısının ekserji verim analizi tek-fazlı durum ve havuz kaynama şartları altında gerçekleştirilecektir. Ekserji yıkımı oranı değerleri nano-parçacık karıştırılmayan saf su sonuçları ve manyetik kuvvete maruz bırakılmayan $\mathrm{Fe}_{3} \mathrm{O}_{4}$ - su nano-sıvısının sonuçları ile karşılaştırılacaktır.

\section{MATERYAL VE YÖNTEM}

$\mathrm{Bu}$ bölümde fiziksel model ve test düzeneğinden bahsedilecektir. Ayrıca, sistemin ekserji analizi için gerekli matematiksek denklemler ve alınan sıcaklık ve manyetik kuvvet verilerinin işlenişi için kullanılan veri indirgeme denklemleri verilecektir. Test düzeneğini oluşturmak için alüminyumdan yapılmış blok içine dört adet fişek isitıcı yerleştirilmiştir. $\mathrm{Bu}$ blok teflondan yapılmış içi boş bir kutuya yerleştirilmiştir. Bunun amacı sistemde sadece yukarıdan aşağıya 1sı transferi (1-boyutlu 1sı transferi) sağlamak yani diğer taraflardan kaybı minimize etmektir, bakınız Şekil 1. Sisteme verilen 1S1, fişek 1sıtıcıların DC güç ünitesine bağlanmasıyla sağlanmıştır ve Eşitlik (1) yardımıyla hesaplanabilir.

$$
P=V \times I
$$

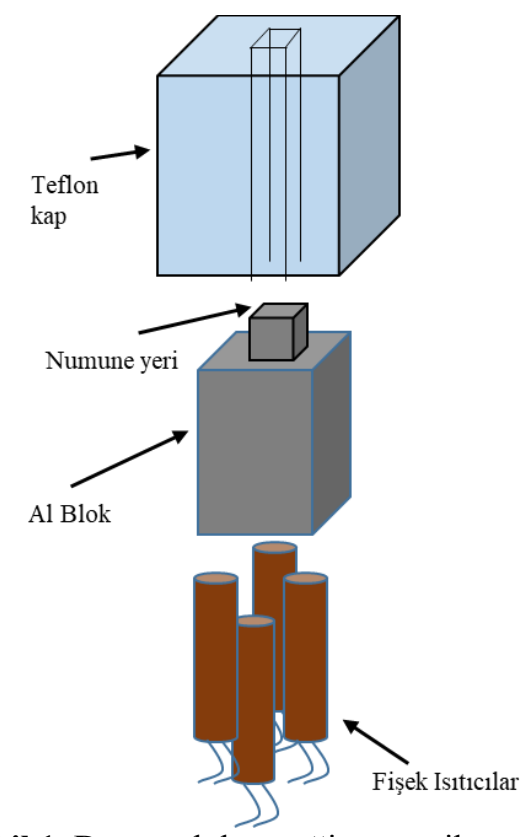

Şekil 1. Deneysel düzeneğin şematik gösterimi

Burada V voltaj girişi ve I sistemin çektiği toplam akımdır. Öte yandan, Alüminyum blok üstüne termal macun yardımıyla silikondan yapılmış test numunesi yerleştirilmiştir. Test numunesinden sıcaklık verileri alüminyum blok içine yerleştirilen $\mathrm{K}$ tipi 1sılçiftler yardımıyla ölçülen duvar-sıcaklık verileri sayesinde alınmıştır, bakınız Şekil 2. Böylece 1-boyutlu 1sı transferi prensibinden numunenin yüzeyindeki sıcaklık
Eşitlik (2) vasıtasıyla hesaplanır. Öte yandan, sistemde sabit 1S1 akısı olması hedeflenmiş olup Eşitlik (3) yardımıla hesaplanabilir.

$$
\begin{aligned}
& T_{s}=T_{w}-q R_{\text {tot }} \\
& q^{\prime \prime}=\frac{\left(P-Q_{\text {loss }}\right)}{A_{h t}}
\end{aligned}
$$

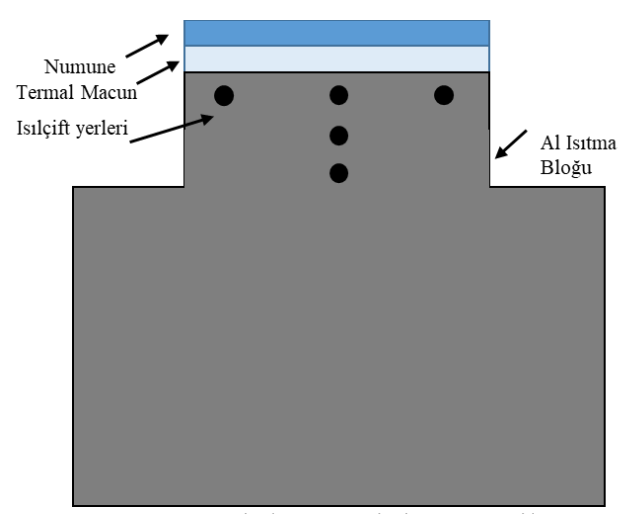

Şekil 2. Test ve veri düzeneğinin şematik gösterimi

Eşitlik (2)'dgki $T_{w}$ alüminyum blok içinde ölçülen duvar sicaklıgı olup $\mathrm{R}_{\text {tot }}$ ise toplam 1sıl dirençtir. Toplam 1sıl direnç, alüminyum blok ve termal macunun kalınlıkları bilgisiyle geleneksel kondüksiyon 1sı transferi hesaplamalarıyla bulunur. Eşitlik (3)'teki, Q Q loss ölçülen 1S1 kayb1 ve $A_{h t}$ numunenin 1Sı transfer alanıdır. Böylece tek-fazlı ve havuz kaynama 1sı transfer katsayıları sırasıyla Eşitlik (4) ve Eşitlik (5) yardımıyla hesaplanabilir.

$h_{s p}=\frac{q^{\prime \prime}}{T_{s}-T_{o}}$

$h_{t p}=\frac{q^{\prime \prime}}{\Delta T_{\text {sat }}}$

Eşitlik (4)'teki $T_{o}$ ortam sıcaklığı olup, Eşitlik (5)'teki $\Delta \mathrm{T}_{\text {sat }}$ yüzey sıcaklığı ile akışkan doyma sıcaklığı arasındaki farktır. Numunenin üst tarafı camdan bir havuz vasıtasıyla kapanmış olup, bu camın iki tarafına manyetik karıştırıcı yerleştirilmiştir. Manyetik karıştırıcılar, deneyler boyunca sisteme sabit $50 \mathrm{rpm}$ açısal dönme hızı sağlamışlardır. Parçacıklar üzerine etki eden manyetik kuvvet Eşitlik (6) yardımıyla hesaplanır.

$F_{\text {mag }}=\frac{\left(X_{p}-X_{c}\right)}{2 \mu_{0}} \forall \nabla B^{2}$

$\mathrm{Bu}$ denklemde, $X_{\mathrm{p}}$ ve $X_{\mathrm{c}}$ sirasiyla manyetik parçacıkların ve suyun manyetik hacim duyarlılığı, $\forall$ 
manyetik kuvvet altındaki hacimdir. Parametreler hakkında daha detaylı bilgi [34, 35] referanslarında bulunabilir. Oluşturulan deney düzeneğine hazırlanan su- $\mathrm{Fe}_{3} \mathrm{O}_{4}$ nano-sıvısı yerleştirilmiş olup deneylere başlanmış ve ölçümler alınmıştır. Deneyler esnasında, 1S1 akısı küçük aralıklarla arttırılmış olup her bir aşamada sıcaklık verileri kaydedilmiştir. Nano-sıvının hazırlanışı ve deney düzeneği hakkında detaylı bilgi için [23] referansı incelenebilir.

Diğer taraftan, eldeki sistem kapalı bir sistem olarak modellenebilir. $\mathrm{Bu}$ durumda kapalı bir sistem için ekserji değişim denklemi genel olarak Eşitlik (7)'de ifade edilebilir, bakınız referans [36].

$$
\begin{aligned}
& {\left[\left(\begin{array}{c}
\text { II.durumdaki } \\
\text { ekserji }
\end{array}\right)-\left(\begin{array}{c}
\text { I.durumdaki } \\
\text { ekserji }
\end{array}\right)\right]=} \\
& {\left[\begin{array}{c}
\text { Isı transferi } \\
\text { sebebiyle } \\
\text { ekserji transferi }
\end{array}\right]-\left[\begin{array}{c}
\text { İș sebebiyle } \\
\text { ekserji transferi }
\end{array}\right]-\left[\begin{array}{c}
\text { Ekserji } \\
\text { yıkmi }
\end{array}\right]}
\end{aligned}
$$

Ekserji değişim Eşitliği (7), belirli uygulamalar için farklı formlarda yazılıp daha pratik bir şekilde sonuca gidilebilir. Kapalı bir sistem için ekserji denge denklemi birim zaman biçiminde pratik olarak Eşitlik (8) olarak yazılır.

$$
\frac{d E}{d t}=\sum_{j}\left(1-\frac{T_{0}}{T_{j}}\right) \dot{Q}_{j}-\left(\dot{W}-p_{0} \frac{d \forall}{d t}\right)-\dot{E}_{d}
$$

Kararlı durum için, Eşitlik (8)'in sol tarafı ve sağ tarafındaki hacim terimi sıfır olur. Böylece, Eşitlik (8) aşağıdaki gibi yazılır ve birim zamandaki ekserji yıkım parametresi elde edilmiş olur.

$0=\sum_{j}\left(1-\frac{T_{0}}{T_{j}}\right) \dot{Q}_{j}-\dot{W}-\dot{E}_{d}$

Sistem kararlı duruma geçtikten sonra, 1Sı akısı küçük aralıklarla arttırılarak her bir adımda gerekli veriler alınmıştır. $\mathrm{Bu}$ işlem, farklı konsantrasyonlardaki ve manyetik kuvvet altında ve altında olmayan tüm numuneler için tekrarlanmıştır. Bütün testler en az iki defa tekrarlanmış olup ölçümlerin tekrarlanabilirliğinden emin olunmuştur. Öte yandan, deneysel belirsizlik analizi de yapılmış olup, ortalama veri belirsizlikleri sıcaklık ölçümleri ve elektriksel güç için \% 2 ekserji yıkım oranı için ise \% 3.2 olarak bulunmuştur.

\section{BULGULAR VE TARTIŞMA}

\subsection{Tek Fazlı Isı Transferi Şartlarındaki Ekserji Sonuçları}

$\mathrm{Bu}$ bölümde, tek-fazlı 1sı transferi şartlarında farklı konsantrasyonlardaki $\mathrm{Fe}_{3} \mathrm{O}_{4}$-su nano-sıvısının ekserji analizi sisteme verilen ısı oranına karşılık gelen ekserji yıkım oranı açısından değerlendirilmiştir. Öte yandan manyetik kuvvet altındaki durumdaki ekserji yıkım oranı ile manyetik kuvvetin olmadığı durumdaki ekserji yıkım oranı karşılaştırılmıştır. Şekil 3 (a-b)'de manyetik kuvvetin olduğu ve olmadığı durumlardaki farklı konsantrasyonlardaki $\mathrm{Fe}_{3} \mathrm{O}_{4}$ nano-sıvisının ekserji yıkım oranları karşılaştırılmıştır.

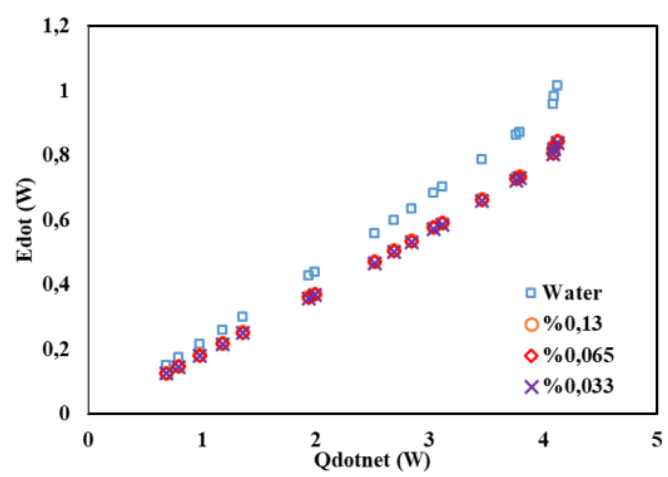

(a)

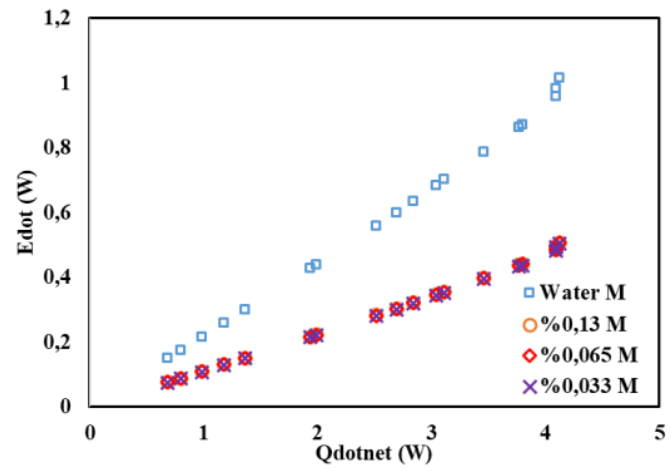

(b)

Şekil 3. Tek-fazlı 1sı transferi şartlarında farklı konsantrasyonlardaki nano-sıvıların ekserji yıkım oranları karşılaştırılması: a) Manyetik kuvvet yokken, b) Manyetik kuvvet varken

Şekil 3 (a-b) 'de açıkça görülmektedir ki, nanosıvıların ekserji yıkım oranı manyetik kuvvet yok iken de var iken de saf suyun ekserji yıkım oranından daha azdır, sırasıyla yaklaşık \% 20 ve \% 75 fark vardır. Şekil 3 (a)'dan da açıkça anlaşılmaktadır ki; nanoparçacıkların sistemin enerji verimliliğinden öte ikinci yasa verimliliğine de pozitif etki etmektedir. Diğer taraftan her iki şekilden de görüldüğü üzere sisteme verilen 1sı arttıkça aradaki fark daha da fazla olmaktadır. Bunun sebebi, sisteme verilen 1s1 arttıkça havuz kaynama şartlarına yaklaşılmaktadır ve havuz kaynama şartlarında nano parçacıkların 1sı transferi daha iyidir, bakınız [20, 24]. Bu sebeple, saf su verisi ile nano-sıvılı veri arasındaki ekserji yıkım oranı farkı gittikçe artmaktadır. Şekil 3 (b)'de ise aynı şartlarda manyetik kuvvet uygulandığı zaman ekserji verimliliği durumu gösterilmektedir. Şekildeki eğilim trendi şekil 3 (a)'daki gibi olmasına rağmen çok açık bir şekilde görülmektedir ki; manyetik kuvvet ekserji verimliliğine pozitif yönde etki etmiştir. İki şekilde de dikkat edilecek diğer bir husus, tek-fazlı 1sı transferi şartlarında nano-parçacık konsantrasyonunun ekserji yıkım oranına etkisinin olmadığıdır. Bu sonuç şaşırtıcı değildir. Literatürdeki çalışmalarda nano-parçacık 
konsantrasyonunun tek fazlı 1s1-transferi verimine etkisinden pek bahsedilmemiştir [24]. Nano-parçacık konsantrasyon etkisi çalışmaları daha çok havuz kaynama ya da akış kaynama şartlarında yapılmış olup tek-faz 1sı transferi şartlarındaki etkisinden bahsedilmemiştir.

Diğer yandan, şekil 4 (a-c)'de nano-sıvıların tek-fazlı 1sı transferi şartlarında manyetik kuvvet altında iken ve manyetik kuvvet olmadan durumdaki ekserji yıkım oranları daha detaylı karşılaştırılmıştır. Görüldüğü üzere manyetik kuvvet altında iken ekserji yıkım oranı diğer duruma göre oldukça düşüktür. Bu sonuçlar enerji verimliliği sonuçları ile paraleldir [23]. Manyetik kuvvet olduğu durumda karışma daha iyi olmakta ve nano-parçacıklar manyetik kuvvetin etkisi ile sürekli hareket halinde döndüklerinden bir nevi is1 taşıyıcısı görevi görerek 1sıtıcıdan sıvıya daha hızlı oranda 1s1 transferi sağlamaktadır. Bunun sonucunda 1sı transferi oranı ve sonucunda enerji verimi manyetik kuvvet olmadığı duruma göre daha fazla olmaktadır. Ekserji yıkım oranı Eşitlik (9)'da görüldüğü üzere sisteme verilen net 1sı oranı ve böylece duvar sıcaklığ1 ve sistemdeki diğer iş yapan kuvvetlerin fonksiyonudur. Buna göre, 1sı transferinin daha iyi olması aynı 1sı oranında duvar sıcaklığının daha yüksek olması ve manyetik kuvvetin etkisi Eşitlik (9)'da ekserji yıkım parametresini daha düşük yapar ve böylece manyetik kuvvet altındaki durumda enerji verimliliği gibi ekserji verimliliği de daha yüksek çıkar.

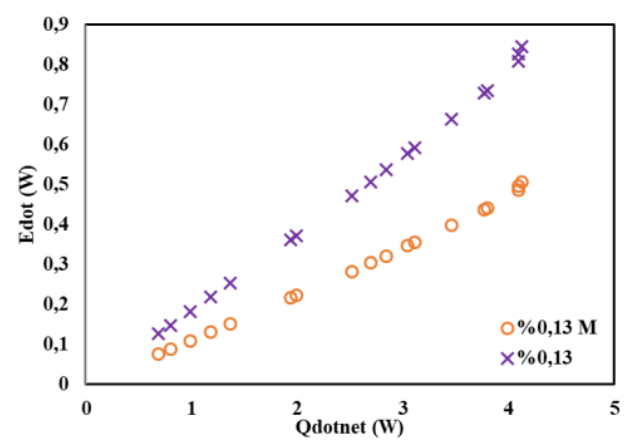

(a)

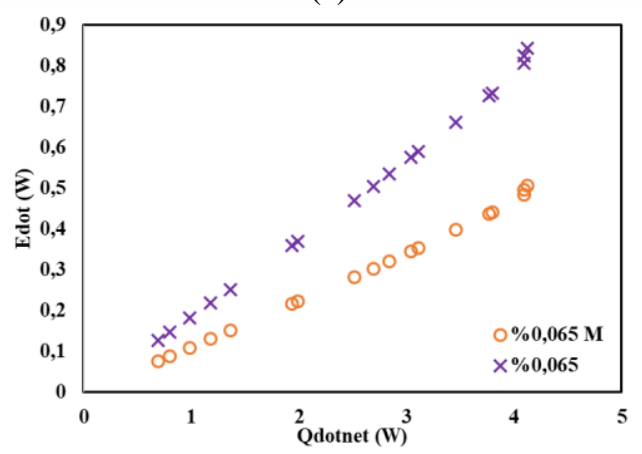

(b)

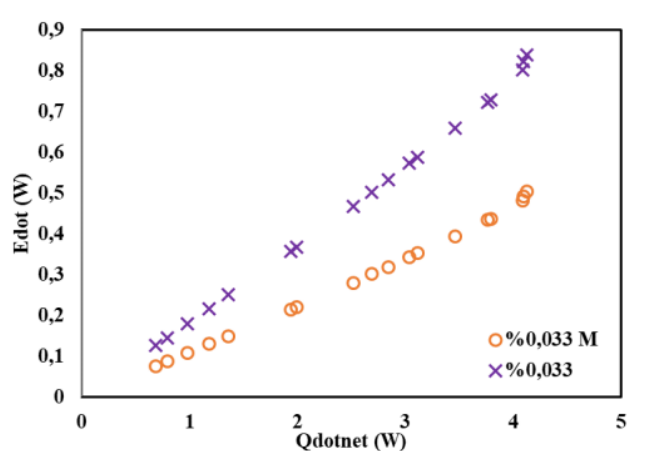

(c)

Şekil 4. Tek-fazlı 1sı transferi şartlarında farklı konsantrasyonlardaki nano-sıvıların manyetik kuvvet varken ve yokken durumda ekserji yıkım oranları karşılaştırılması: a) \% 0,13 konsantrasyonu için, b) \% 0,065 konsantrasyonu için, c) $\% 0,033$ konsantrasyonu için

\subsection{Havuz Kaynama Isı Transferi Şartlarındaki Ekserji Sonuçları}

$\mathrm{Bu}$ bölümde, havuz kaynama 1sı transferi şartlarında farklı konsantrasyonlardaki $\mathrm{Fe}_{3} \mathrm{O}_{4}$-su nano-sıvisının ekserji analizi sisteme verilen 1sı oranına karşılık gelen ekserji yıkım oranı açısından değerlendirilmiş ve sonuçlar manyetik kuvvet altındaki durumdaki ekserji yıkım oranı ile manyetik kuvvetin olmadığı durumdaki ekserji yıkım oranı ile karşılaştırılması şeklinde sunulmuştur. Şekil 5 (a-b)'de havuz kaynama 1s1 transferi şartlarında farklı konsantrasyonlardaki nanosıvıların ekserji yıkım oranları manyetik kuvvet altında ve manyetik kuvvet yokken sunulmuştur. Tek-fazlı 1s1 transferi şartlarındaki gibi havuz kaynama şartlarında da nano-sıvıların ekserji yıkım oranı saf suyunkinden azdır. Aradaki fark manyetik kuvvet altında iken daha da açılmaktadır. Öte yandan, tek-fazlı akış şartlarında verilerin trendin eğimi havuz kaynama şartlarındaki verilerin lineer eğilimin daha düşüktür. Bunun sebebi açıkça, nano-sıvıların daha fazla aktif parçacık bölgesi oluşturarak havuz kaynama şartlarında daha yüksek 1s1 transferi oranı sağlaması dolayısıyla daha düşük ekserji yıkım oranı sağlayabilmesidir.

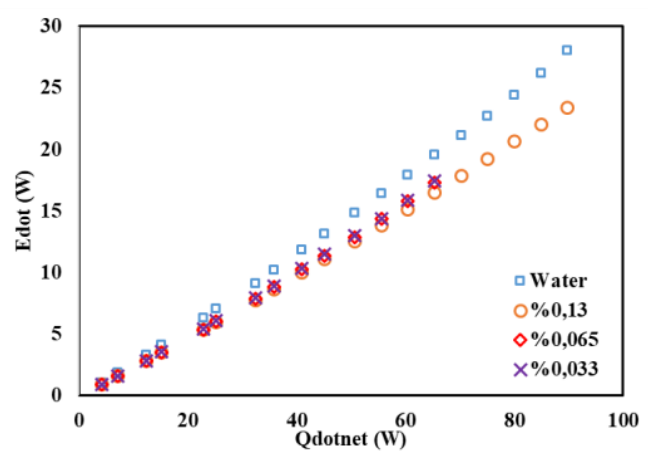

(a) 


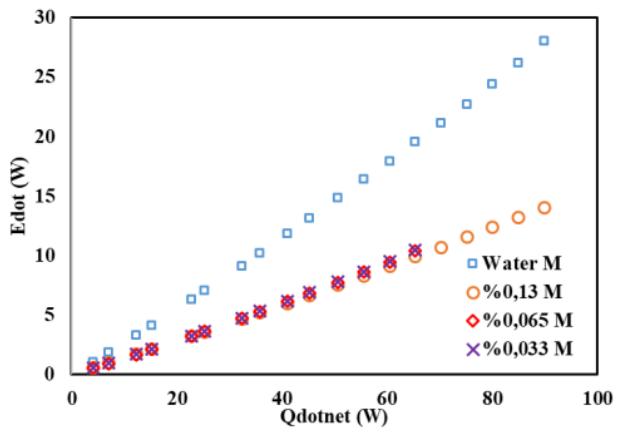

(b)

Şekil 5. Havuz kaynama 1sı transferi şartlarında farklı konsantrasyonlardaki nano-sıviların ekserji yıkım oranları karşılaştırılması: a) Manyetik kuvvet yokken, b) Manyetik kuvvet varken

$\mathrm{Bu}$ bulgulara ek olarak, her iki şekilde de konsantrasyonun ekserji yıkımna etkisi görülmemiştir. $\mathrm{Bu}$ sonuçlar, tek fazlı isı transferi şartlarındaki sonuçlara benzerdir. Literatürde, havuz kaynama ve akış kaynama ısı transferi şartlarında genellikle nanoparçacık yoğunluğu ile 1sı transferinin belli bir noktaya kadar doğru orantılı olarak arttığı fakat bu noktadan sonra nano-parçacık yoğunluğu artışının çökelme ve kümelenmeden ötürü 1sı transferine negatif yönde etki ettiği belirtilmiştir [37, 38]. Çünkü yüksek konsantrasyonda daha yüksek kabarcık yoğunluğu olur ve kalabalıktan ötürü numune yüzeyinin 1slanması zorlaşır ve 1Sı transferi negatif olarak etkilenir. Lakin 1s1 transferi veriminin aksine ekserji veriminde bu durum söz konusu olmamaktadır, bakınız Şekil 5 (a-b). Nano-sıvi konsantrasyonunun ekserji yıkım oranına etki etmemesinin sebebi, muhtemelen ekserji y1kım oranının duvar sıcaklığının fonksiyonu olmasıdır. Daha önce de bahsedildiği gibi, ekserji yıkım oranı Eşitlik (9) yardımıyla hesaplanabilir. Nano-sıvı fraksiyonu değişimi sisteme verilen aynı 1sı oranında duvar sıcaklığına etki edecek kadar güçlü olmamıştır. Öte yandan, sistemde manyetik kuvvetin varlığı direkt olarak Eşitlik (9)'a etki edeceğinden ekserji yıkım parametresini daha düşük yaparak ekserji oranını düşürür, bakınız Şekil 6 (a-c). Şekil 6 (a-c)'de havuz kaynama 1şartlarında manyetik kuvvet altında iken ve manyetik kuvvet olmadan durumdaki ekserji yıkım oranları daha detaylı karşılaştırılmıştır. Görüldüğü üzere tüm konsantrasyonlardaki nano-sıvilarda manyetik kuvvet varken ekserji yıkım oranı manyetik kuvvet olmadığı duruma göre epeyce azdır. Bu sonuçlar bu nano-sıviların isı transferi performansları ile paraleldir, bakınız referans [23]. Özdemir vd. [23], manyetik kuvvetin yukarı doğru dış ekstra bir kuvvet oluşturduğu için kabarcık ayrılış prosesine pozitif yönde etki ettiğini belirtmiştir. Yazarlar buna ek olarak, manyetik kuvvetin havuz içerisinde sirkülasyonu arttırdığı ve böylece taşınım ısı transferini hızlandırdığını raporlamıştır. Yazarlar bu bulgularını kamera sonuçlarıyla ve nümerik analiz programlarıyla doğrulamışlardır. Bu durumun sebebi aslında oldukça açıktır. Isı transferini arttıran iki temel mekanizma termoforez ve parçacıkların rastgele hareketidir.
Manyetik kuvvet bunlardan ikinci mekanizma olan rastgele hareketi ciddi manada arttırmakta ve böylece 1Sı transferi artmaktadır. Hareketin artması çökelme ve kümelenmenin de çok daha geç olmasını sağlamış ve bu durum 1sı transferine pozitif yönde etki etmiştir. Isı transferi artması demek duvar sicaklığı ile doyma sıcaklığı arasındaki farkın artması demektir. Doyma sıcaklığı sisteme verilen 1sı transferi oranı ile orantılı olduğundan buradaki fark manyetik kuvvetin duvar sıcaklığının daha da artmasını sağlamasından kaynaklanmaktadır. Duvar sıcaklığının artması da ekserji yıkım oranı parametresini düşüreceğinden entropi üretimi düşecektir. Entropi üretiminin düşmesi demek ikinci yasa verimliliğinin artmasına katkı sağlamak demektir. Bu sonuçlardan da anlaşılacağı üzere manyetik kuvvet $\mathrm{Fe}_{3} \mathrm{O}_{4}$-su nano-sıvilarına birinci yasa verimliliğinin yanı sıra ikinci yasa verimliliği açısından da katkı sağlamaktadır. Ekserji yıkım oranı manyetik kuvvet altında önemli ölçüde düşmüştür.

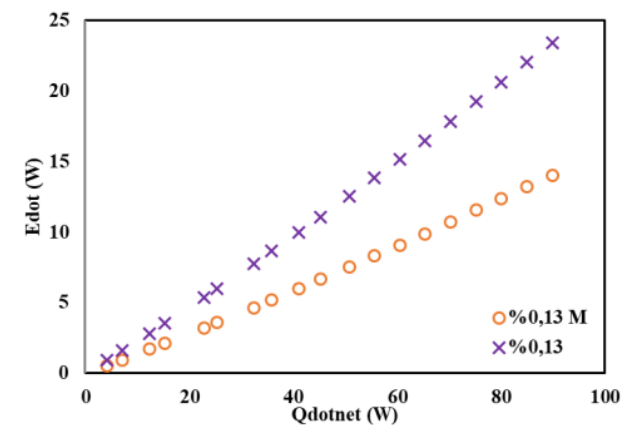

(a)

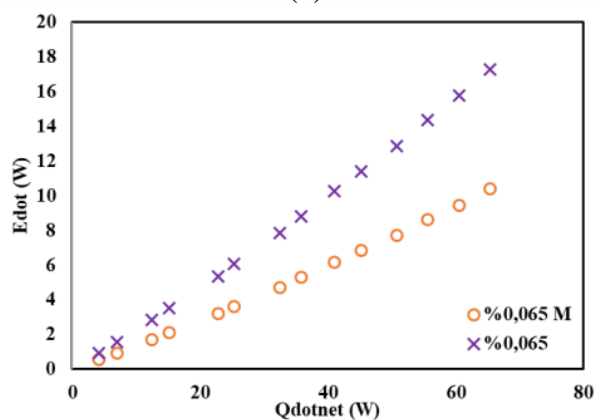

(b)

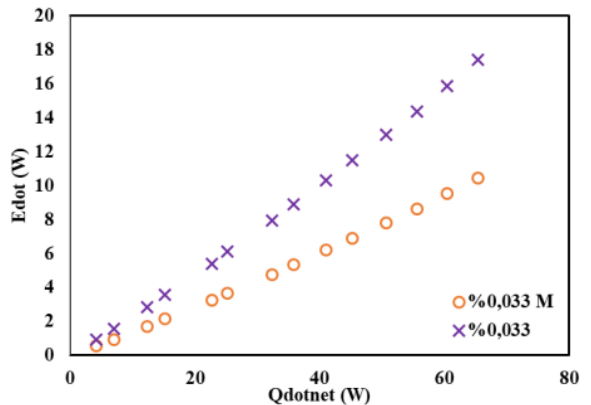

(c)

Şekil 6. Havuz Kaynama 1sı transferi şartlarında farklı konsantrasyonlardaki nano-sıviların manyetik kuvvet varken ve yokken durumda ekserji yıkım oranları karşılaştırılması: a) \% 0,13 konsantrasyonu için, b) \% 0,065 konsantrasyonu için, c) \% 0,033 konsantrasyonu için 


\section{SONUÇ VE DEĞERLENDİRMELER}

$\mathrm{Bu}$ çalışmada, son yıllarda çokça tercih edilen 1s1 transferi arttırma yöntemlerinden biri olan baz sıvıya nano-parçacık ekleme metodunun ikinci yasa analizi yapılmıştır. Üç farklı konsantrasyonlarda hazırlanan $\mathrm{Fe}_{3} \mathrm{O}_{4}$-su nano sivisinın manyetik kuvvet altında ve manyetik kuvvet olmadığı durumdaki ekserji verimlilikleri tek-fazlı ısı transferi şartlarında ve havuz kaynama ısı transferi şartlarında sunulmuştur. Ekserji verimliliği analizi ekserji yıkım oranı parametresi cinsinden sunulmuştur. Sonuçlara göre, hem tek fazlı 1S1 transferi hem de havuz kaynama 1s1 transferi şartlarında nano-sıvıların ekserji verimliliği ana sıvı olan saf suyunkinden daha fazladır. Öte yandan her iki 1s1 transferi şartlarında da manyetik kuvvetin olduğu durumda ekserji verimliliği manyetik kuvvet olmayan duruma göre daha yüksek olarak bulunmuştur. Lakin havuz kaynama 1sı transferi şartları altında manyetik kuvvetin ekserji verimliliğini iyileştirmesi tek fazlı 1s1 transferi şartlarından daha iyi olarak gözükmüştür. Bunun sebebi, manyetik kuvvetin kabarcıkların hareketini hızlandırması ve dolayısıyla 1sı transferini arttırması ve duvar sıcaklığını arttırmasıdır. Öte yandan artan duvar sicaklığı ve oluşan manyetik kuvvet ekserji yıkımını azaltarak ekserji verimliliğinin artmasına sebep olmuştur. Ekserji verimliliği sonuçları enerji verimliliği sonuçları ile paralel olduğundan nano-sıviların ana sıvilarına kıyasla daha tercih edilebilir olduğu ikinci yasa analizi ile doğrulanmıştır. Diğer taraftan, son zamanlarda birkaç çalışmada yer alan manyetik nano-parçacık kullanarak nano-sıvı oluşturma ve manyetik kuvvetle bu oluşan nano-sıvıya ekstra 1Sı transferi performansı kazandırma işlemi de ikinci yasa bağlamında incelenmiş olup sonuçlar olumlu bulunmuştur. $\mathrm{Bu}$ sonuçların 1şı̆̆ 1 altında, manyetik kuvvet kullanımının manyetik nanoparçacıklı sistemlerin verimliliğine pozitif yönde etki ettiği ve literatür için bu çalışmalara devam edilebileceği söylenebilir.

\section{SEMBOLLER}

$A_{h t}:$ Isı transferi alanı $\left(\mathrm{m}^{2}\right)$

B: Manyetik akı yoğunluğu (T)

$\dot{E}_{d}$ : Ekserji yıkım oranı (W)

$\mathrm{F}_{\text {mag: }}$ : Manyetik kuvvet $(\mathrm{N})$

$\mathrm{h}_{\mathrm{sp}}$ : Tek-fazlı 1 sı transferi katsayıs $\left(\mathrm{W} / \mathrm{m}^{2}{ }^{\circ} \mathrm{C}\right)$

$\mathrm{h}_{\text {tp }}$ : Kaynama $1 \mathrm{~s} 1$ transferi katsayıs $\left(\mathrm{W} / \mathrm{m}^{2}{ }^{\circ} \mathrm{C}\right)$

I : Akım (A)

$\mathrm{P}:$ Güç (W)

$\mathrm{Q}_{\text {loss }}$ : Isı enerjisi kayb1 (W)

$\dot{Q}_{n e t}$ : Sisteme verilen net 1si enerjisi (W)

$\mathrm{q}:$ Is1 Enerjisi (W)

q" : Is1 ak1s1 $\left(\mathrm{W} / \mathrm{m}^{2}\right)$

$\mathrm{p}_{0}:$ Referans basınç $(\mathrm{Pa})$

$\mathrm{R}_{\text {tot }}$ : Toplam 1 sıl direnç $\left({ }^{\circ} \mathrm{C} / \mathrm{W}\right)$

$\mathrm{T}_{\mathrm{o}}$ : Ortam sicaklığ $1\left({ }^{\circ} \mathrm{C}\right)$

$\mathrm{T}_{\mathrm{s}}$ : Yüzey sıcaklığ $\left({ }^{\circ} \mathrm{C}\right)$

$\mathrm{T}_{\mathrm{w}}$ : Duvar sicaklı̆̆ $1\left({ }^{\circ} \mathrm{C}\right)$
$\mathrm{V}:$ Voltaj (V)

$\dot{W}$ : İş yoluyla enerji transferinin oranı $(\mathrm{W})$

$X_{c}$ : Suyun parçacıkların hacim duyarlılı̆̆ $\left(\mathrm{m}^{3} / \mathrm{mol}\right)$

$\mathrm{X}_{\mathrm{p}}$ : Manyetik parçacıkların hacim duyarlılığ $1\left(\mathrm{~m}^{3} / \mathrm{mol}\right)$

$\Delta \mathrm{T}_{\text {sat }}$ : Yüzey sıcaklığı ve akışkanın doyma sıcaklığı arasındaki fark (-)

$\mu_{0}$ : Boş alan geçirgenliği $\left(\mathrm{N} / \mathrm{A}^{2}\right)$

$\forall$ : Manyetik kuvvet altındaki hacim $\left(\mathrm{m}^{3}\right)$

\section{TEŞEKKÜR}

Bu çalışma, Marmara Üniversitesi Bilimsel Araştırma Projeleri Komitesi tarafindan (BAPKO) ile FEN-D120619-0204 numaralı hibe numarası ile desteklenmiştir.

\section{KAYNAKLAR}

[1] Karayiannis, T.G., \& Mahmoud, M.M., (2017). Flow boiling in microchannels: Fundamentals and applications. Applied Thermal Engineering, $115,1372-1397$.

[2] Mudawar, I., (2011). Two-phase microchannel heat sinks: theory, applications, and limitations. Journal Of Electronic Packaging, 133(4), 2-33.

[3] Kaya, A., Özdemir, M.R., \& Koşar, A., (2013). High mass flux flow boiling and critical heat flux in microscale. International Journal of Thermal Sciences, 65, 70-78.

[4] Kang, S.W., Chen, Y.T., \& Chang, G.S., (2002). The manufacture and test of (110) orientated silicon based micro heat exchanger. Tamkang Journal of Science and Engineering, 5(3), 129136.

[5] Özdemir, M.R., Kaya, A., \& Koşar, A., (2011). Low mass quality flow boiling in microtubes at high mass fluxes. Journal of Thermal Science and Engineering Applications, 3(4), 1-10.

[6] Yang, B., Wang, P., \& Bar-Cohen, A., (2007). Mini-contact enhanced thermoelectric cooling of hot spots in high power devices. IEEE Transactions on Components and Packaging Technologies, 30(3), 432-438.

[7] Sajid, M.U., \& Ali, H.M., (2019). Recent advances in application of nanofluids in heat transfer devices: a critical review. Renewable and Sustainable Energy Reviews, 103, 556-592.

[8] Xu, H.J., Xing, Z.B., Wang, F.Q., \& Cheng, Z.M., (2019). Review on heat conduction, heat convection, thermal radiation and phase change heat transfer of nanofluids in porous media: Fundamentals and applications. Chemical Engineering Science, 195, 462-483.

[9] Hassan, M., Marin, M., Alsharif, A., \& Ellahi, R., (2018). Convective heat transfer flow of nanofluid in a porous medium over wavy surface. Physics Letters A, 382(38), 2749-2753.

[10] Ebrahimnia-Bajestan, E., Moghadam, M.C., Niazmand, H., Daungthongsuk, W., \& Wongwises, S., (2016). Experimental and numerical investigation of nanofluids heat 
transfer characteristics for application in solar heat exchangers. International Journal of Heat and Mass Transfer, 92, 1041-1052.

[11] Kakaç, S., \& Pramuanjaroenkij, A., (2009). Review of convective heat transfer enhancement with nanofluids. International Journal of Heat and Mass Transfer, 52(13-14), 3187-3196.

[12] Murshed, S.M.S., Leong, K.C., \& Yang, C., (2005). Enhanced thermal conductivity of $\mathrm{TiO} 2$ - water based nanofluids. International Journal of Thermal Sciences, 44(4), 367-373.

[13] Sundar, L.S., Singh, M.K., \& Sousa, A.C., (2013). Investigation of thermal conductivity and viscosity of $\mathrm{Fe}_{3} \mathrm{O}_{4}$ nanofluid for heat transfer applications. International Communications in Heat and Mass Transfer, 44, 7-14.

[14] Motezakker, A.R., Sadaghiani, A.K., Akkoc, Y., Parapari, S.S., Gözüaçık, D., \& Koşar, A., (2017). Surface modifications for phase change cooling applications via crenarchaeon Sulfolobus solfataricus P2 bio-coatings. Scientific reports 17891, 7(1), USA.

[15] Sadaghiani, A.K., Motezakker, A.R., Kasap, S., Kaya, I.I., \& Koşar, A., (2018). Foamlike 3D graphene coatings for cooling systems involving phase change. ACS Omega, 3(3), 2804-2811.

[16] Kim, S.H., Lee, G.C., Kang, J.Y., Moriyama, K., Kim, M.H., \& Park, H.S., (2015). Boiling heat transfer and critical heat flux evaluation of the pool boiling on micro structured surface. International Journal of Heat and Mass Transfer, 91, 1140-1147.

[17] Kim, B.S., Choi, G., Shim, D.I., Kim, K.M., \& Cho, H.H., (2016). Surface roughening for hemiwicking and its impact on convective boiling heat transfer. International Journal of Heat and Mass Transfer, 102, 1100-1107.

[18] Buongiorno, J., (2015). Convective transport in nanofluid, Journal of Heat Transfer, 128(3), 240250.

[19] Godson, L., Raja, B., Lal, D.M., \& Wongwises, S., (2010). Enhancement of heat transfer using nanofluids-an overview. Renewable and sustainable energy reviews, 14(2), 629-641.

[20] Şeşen, M., Tekşen, Y., Şahin, B., Şendur, K., Pınar Mengüç, M., \& Koşar, A., (2013). Boiling heat transfer enhancement of magnetically actuated nanofluids. Applied Physics Letters, 102(16), 163107.

[21] Kurtoğlu, E., Bilgin, A., Şeşen, M., Yıldız, M., Acar, H.F.Y., \& Koşar, A., (2012). Ferrofluid actuation with varying magnetic fields for micropumping applications. Microfluidics and Nanofluidics, 13(4), 683-694.

[22] Zuvin, M., Koçak, M., Ünal, Ö., Akkoç, Y., Kutlu, Ö., Acar, H.F.Y., Gözüaçik, D., \& Koşar, A., (2019). Nanoparticle based induction heating at low magnitudes of magnetic field strengths for breast cancer therapy. Journal of Magnetism and Magnetic Materials, 483, 169-177.
[23] Özdemir, M.R., Sadaghiani, A.K., Motezakker, A.R., Parapari, S.S., Park, H.S., Acar, H.F.Y., \& Koşar, A., (2018). Experimental studies on ferrofluid pool boiling in the presence of external magnetic force. Applied Thermal Engineering, 139, 598-608.

[24] Şeşen, M., Tekşen, Y., Şendur, K., Pınar Mengüç, M., Öztürk, H., Acar, H.F.Y., \& Koşar, A., (2012). Heat transfer enhancement with actuation of magnetic nanoparticles suspended in a base fluid. Journal of Applied Physics, 112(6), 320326.

[25] Bejan, A., (2016). Entropy generation and exergy destruction. In: Advanced Thermodynamics, 4. Bask1, John Wiley \& Sons, USA, s. 95-140.

[26] Gümüş, M., \& Atmaca, M., (2013). Energy and Exergy Analyses Applied to a CI Engine Fueled with Diesel and Natural Gas. Energy Sources, Part A: Recovery, Utilization, and Environmental Effects, 35, 1017 - 1027.

[27] Kanoglu, M., Dincer, I., \& Rosen, M.A., (2008). Exergetic performance investigation of a turbocharged stationary diesel engine. International Journal of Exergy, 5(2), 193-203.

[28] Rosen, M.A., Dincer, I., \& Kanoglu, M., (2008). Role of exergy in increasing efficiency and sustainability and reducing environmental impact. Energy policy, 36(1), 128-137.

[29] Khaleduzzaman, S.S., Sohel, M.R., Saidur, R., Mahbubul, I.M., Shahrul, I.M., Akash, B.A., \& Selvaraj, J., (2014). Energy and exergy analysis of alumina-water nanofluid for an electronic liquid cooling system. International Communications in Heat and Mass Transfer, 57, 118-127.

[30] Esfahani, M.R., \& Languri, E.M. (2017). Exergy analysis of a shell-and-tube heat exchanger using graphene oxide nanofluids. Experimental Thermal and Fluid Science, 83, 100-106.

[31] Said, Z., Saidur, R., \& Rahim, N.A., (2016). Energy and exergy analysis of a flat plate solar collector using different sizes of aluminium oxide based nanofluid. Journal of Cleaner Production, 133, 518-530.

[32] Mukherjee, S., Mishra, P.C., \& Chaudhuri, P., (2019). Energy and Exergy Viability Analysis of Nanofluids As A Coolant for Microchannel Heat Sink. International Journal of Automotive and Mechanical Engineering, 16(1), 6090-6107.

[33] Fayaz, H., Nasrin, R., Rahim, N.A., \& Hasanuzzaman, M., (2018). Energy and exergy analysis of the PVT system: Effect of nanofluid flow rate. Solar Energy, 169, 217-230.

[34] Juha, P., Tapani, J., \& Valeria, H., (2009). Design of magnetic circuits. In: Design of rotating electrical machines, 2. bask1, Wiley, USA, s. 155227.

[35] Sagawa, M., Fujimura, S., Togawa, N., Yamamoto, H., \& Matsuura, Y., (1984). New material for permanent magnets on a base of $\mathrm{Nd}$ 
and Fe. Journal of Applied Physics, 55(6), 20832087.

[36] Moran, M.J., Shapiro, H.N., Boettner, D.D., \& Bailey, M.B., (2010). Exergy Analysis. In: Fundamentals of engineering thermodynamics, 9. bask1, Wiley, USA, s. 272-315.

[37] Karimzadehkhouei, M., Şendur, K., Mengüç, M.P., \& Koşar, A., (2017). The eff ect of nanoparticle type and nanoparticle mass fraction on heat transfer enhancement in pool boiling. International Journal of Heat and Mass Transfer, 109, 157-166.

[38] Reddy, P.S., \& Chamkha, A.J., (2016). Influence of size, shape, type of nanoparticles, type and temperature of the base fluid on natural convection MHD of nanofluids. Alexandria Engineering Journal, 55(1), 331-341. 